\title{
A NEW SPECIES OF ORIBATID MITES OF THE GENUS PERSCHELORIBATES (ACARI, ORIBATIDA, SCHELORIBATIDAE) FROM CUBA
}

\author{
Sergey G. Ermilov* and Andrei V. Tolstikov
}

Tyumen State University, Tyumen, Russia

*corresponding author; e-mail: ermilovacari@yandex.ru

ABSTRACT: Anew species of the genus Perscheloribates-P. (Perscheloribates) curiosus Ermilov sp. n. - is described and illustrated on the basis of adult specimens collected from leaf litter in forests of Cuba. The new species is morphologically most similar to $P$. (Perscheloribates) luzonensis Corpuz-Raros, 1980; however, it differs from the latter by the presence of bothridial setae pointed distally (vs. rounded), custodia (vs. absent) and well visible notogastral setae (vs. posterior setae hardly visible, other setae represented by alveoli).

KEY WORDS: Oribatid mites, Scheloribatidae, new taxa, morphology, systematics, fauna, Cuba.

DOI: 10.21684/0132-8077.2016.24.1.27.32

\section{INTRODUCTION}

Ermilov (2016) presented the checklist of Oripodoidea (Acari, Oribatida) collected from Cuba. One species was not identified and was listed as Perscheloribates sp. (Scheloribatidae). Based on literature information, this species is morphologically similar to Scheloribates (Scheloribates) feideri Călugăr et Vasiliu, 1983. Taking into account that the authors (Călugăr and Vasiliu 1983) did not note the number of leg claws, which is the main difference between Scheloribates Berlese, 1908 and Perscheloribates Hammer, 1973 in their paper, the study of type material was necessary for morphological comparison.

We loaned the paratypes of $S$. (Scheloribates) feideri and compared them with the specimens of Perscheloribates sp. We established that these two species clearly differ, and the generic position of $S$. (Scheloribates) feideri is correct, because it has three claws on all legs.

Thus, the main goal of the paper is to describe and illustrate the new species of the genus Perscheloribates under the name of $P$. (Perscheloribates) curiosus Ermilov sp. n.

The genus Perscheloribates was proposed by Hammer (1973) with Perscheloribates clavatus Hammer, 1973 as type species. Currently, it comprises four subgenera and about 50 species (Subías 2004, updated 2015; Ermilov et al. 2015), which are distributed in the tropical and subtropical regions (Subías 2004, updated 2015). The main generic and subgeneric characters were summarized by Hammer (1973), Corpuz-Raros (1980), Balogh and Balogh (1990, 1992), Ermilov and Kalúz (2012), and Ermilov et al. (2013). The identification keys for many species of the Neotropical region were presented earlier by Balogh and Balogh (1990, 2002), from the Ethiopian and Oriental regions by
Ermilov et al. (2011), and Ermilov and Martens (2014).

\section{MATERIAL AND METHODS}

The collection locality and habitat for the new species is given in the Material examined section.

Specimens were mounted in lactic acid on temporary cavity slides for measurement and illustration. The body length was measured in lateral view, from the tip of the rostrum to the posterior edge of the ventral plate. Notogastral width refers to the maximum width in dorsal aspect. Lengths of body setae were measured in lateral aspect. All body measurements are presented in micrometers $(\mu \mathrm{m})$. Formulas for leg setation are given in parentheses according to the sequence trochanter-femur-genu-tibia-tarsus (famulus included). Formulas for leg solenidia are given in square brackets according to the sequence genutibia-tarsus. General terminology used in this paper follows mostly that of F. Grandjean (summarized by Norton and Behan-Pelletier 2009). Drawings were made with a drawing tube using a Carl Zeiss transmission light microscope "Axioskop-2 Plus".

\section{TAXONOMY}

\section{Perscheloribates (Perscheloribates) curiosus Ermilov sp. $\mathrm{n}$.}

Figs 1-12

Diagnosis. Body size: $258-316 \times 159-192$. Body surface smooth. Rostrum protruding, pointed. Prolamellae and keel-shaped ridges absent. Rostral, lamellar, and interlamellar setae long, setiform, barbed. Bothridial setae with heads dilated unilaterally, barbed. Notogastral setae present, minute. 
S. G. Ermilov and A. V. Tolstikov
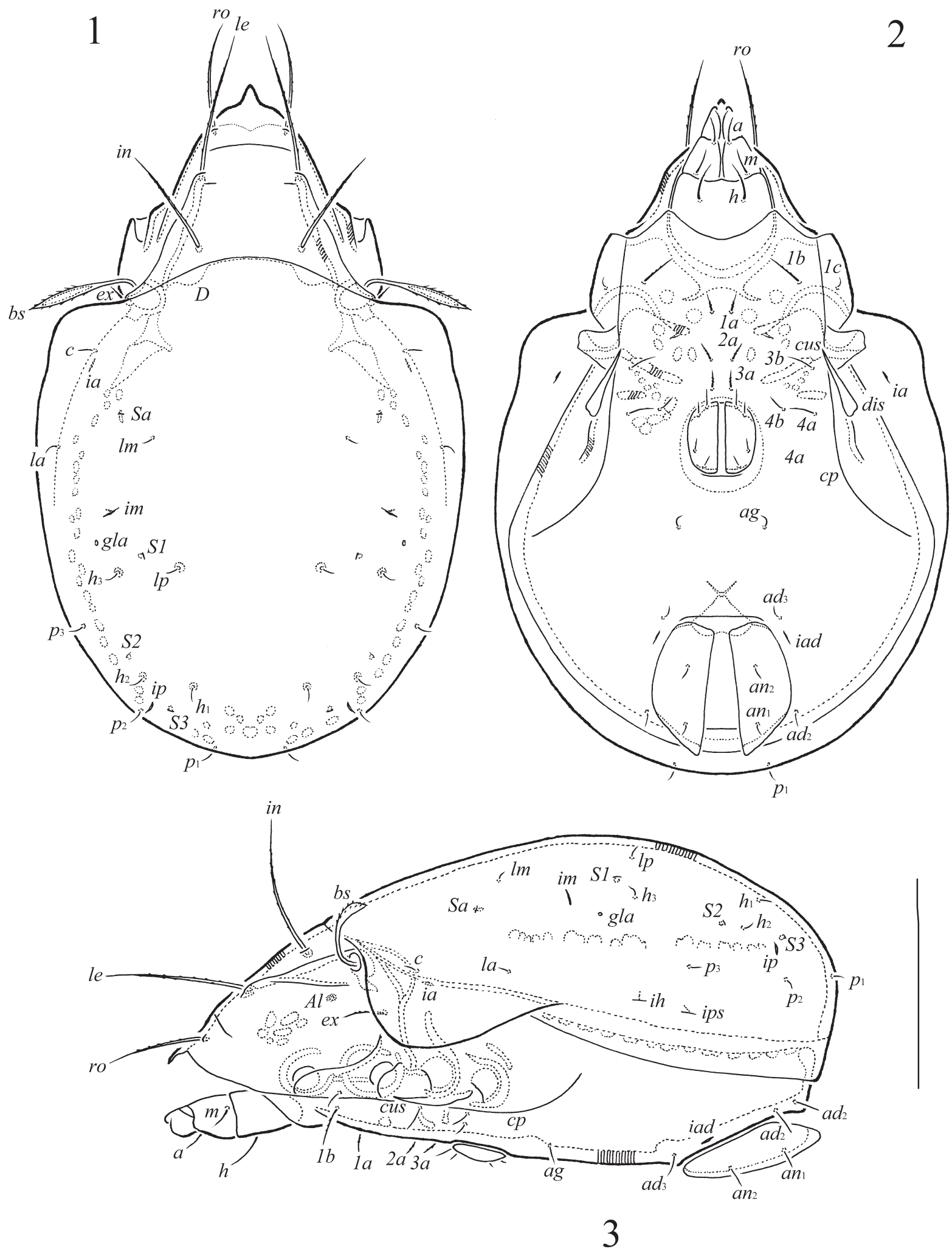

Figs 1-3. Perscheloribates (Perscheloribates) curiosus Ermilov sp. n., adult: 1-dorsal view; 2-ventral view (legs not illustrated); 3-lateral view (legs not illustrated). Scale bars $100 \mu \mathrm{m}$. 

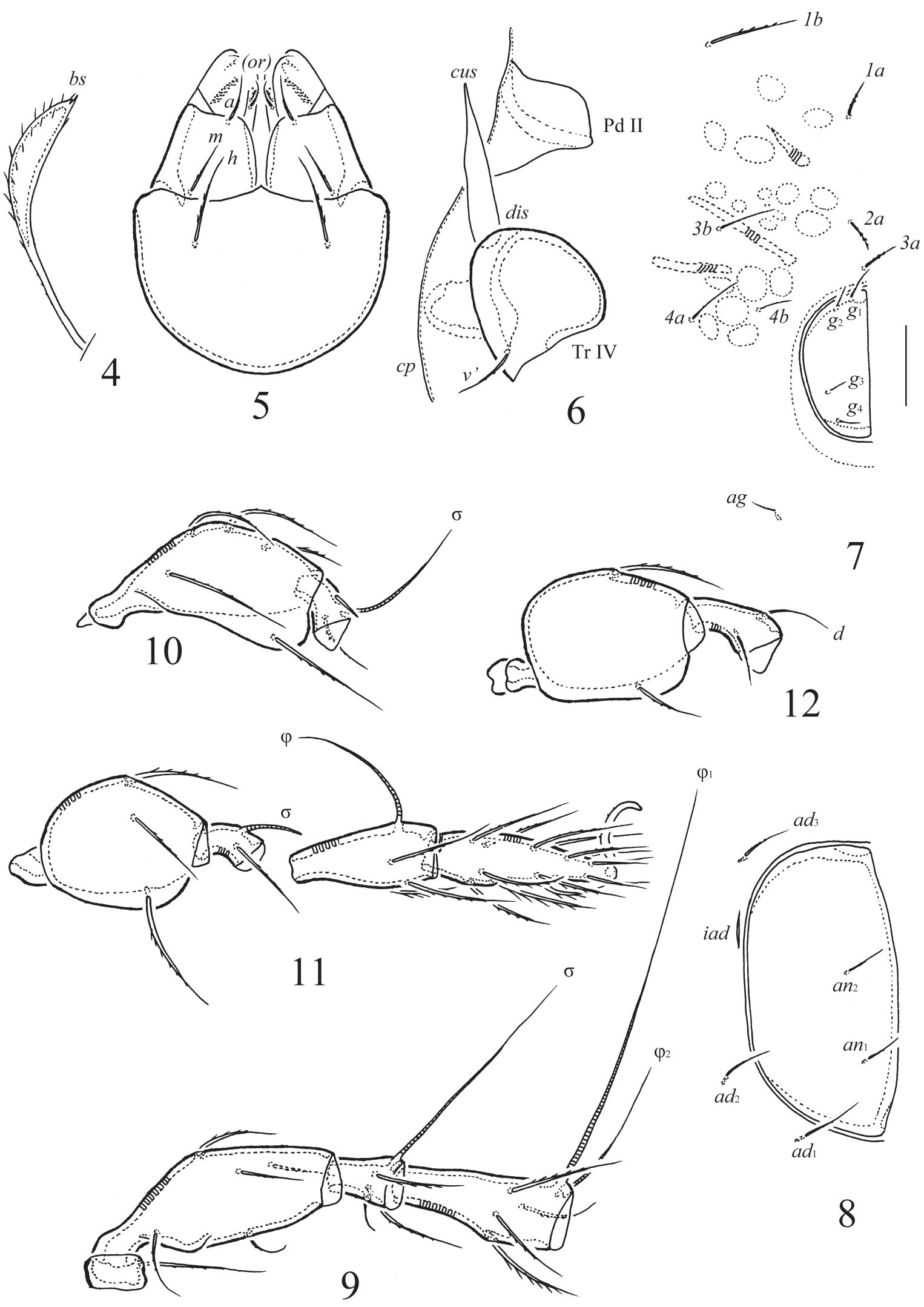

Figs 4-12. Perscheloribates (Perscheloribates) curiosus Ermilov sp. n., dissected adult: 4-bothridial seta; 5-subcapitulum, ventral view; 6-part of left podosomal region, ventral view; 7-part of right epimeral and genitoaggenital regions; 8-part of right adanal region; 9-leg I, except tarsus, right, antiaxial view; 10-femur and genu of leg II, right, antiaxial view; 11-leg III, except trochanter, left, antiaxial view; 12-femur and genu of leg IV, left, antiaxial view. Scale bar $20 \mu \mathrm{m}$. 
Setae $h$ longest on subcapitulum. Epimeral setal formula: 3-1-2-2 (3c and $4 c$ absent). Setae $1 a, 2 a$ and $3 a$ heavily barbed, other setae indistinctly barbed. Custodia well-developed. Anogenital setae comparatively short, indistinctly barbed. Leg claws with barbs on dorsal side. Tarsi I with 20 setae.

Description. Measurements. Females larger than males. Body length: 274 (holotype: male), 307-316 (seven paratypes: females), 258-287 (seven paratypes: males); notogaster width: 164 (holotype), 184-192 (seven paratypes: females), 159-164 (seven paratypes: males).

Integument. Body color yellow-brownish. Body surface smooth.

Prodorsum. Rostrum with distinct, narrow protruding, pointed apically. Lamellae located dorso-laterally, half as long as prodorsum (measured in lateral view). Prolamellae absent. Sublamellae slightly shorter than lamellae. Translamellar line represented by two short, rudimentary parts near to lamellae. Sublamellar porose areas $(A l)$ rounded (6). Keel-shaped ridges absent. Rostral (ro, 41-49), lamellar (le, 57-65) and interlamellar (in, 57-65) setae setiform, barbed. Exobothridial setae (ex, 18-20) thin, slightly barbed. Bothridial setae (bs, 60-68) with longer (32-36) stalks and heads shorter (28-32), dilated unilaterally (see in lateral view), barbed. Sejugal porose areas not visible.

Notogaster. Anterior notogastral margin convex medially. Dorsophragmata $(D)$ semi-oval. Ten pairs of notogastral setae short (8), thin, smooth. Four pairs of saccules $(S a, S 1, S 2, S 3)$ with small openings and short channels. Setae $l m$ inserted medio-posteriorly to $S a$, setae $l p$ inserted laterally to $S 1$. Lyrifissures (ia, im, ip, ih, ips) and opisthonotal gland openings ( $g l a)$ clearly visible.

Gnathosoma. Morphology typical for Perscheloribates (see Ermilov et al. 2011). Subcapitulum longer than wide $(82-86 \times 61-65)$. Subcapitular setae setiform, $a$ and $m$ (both pairs 16-18) indistinctly barbed, $h$ (24-26) slightly thicker, well barbed. Two pairs of adoral setae $\left(o r_{1}, o_{2}, 10\right)$ setiform, barbed. Palps (length 41-45) with setation $0-2-1-3-9(+\omega)$. Solenidion of palptarsi attached to eupathidium, both located on dorsal tubercle. Chelicerae (length 77-82) with two barbed setae, cha (24) longer than chb (12-14). Trägårdh's organ tapered.

Epimeral and lateral podosomal regions. Apodemes 2 and 3 shorter than sejugal apodemes. Epimeral setal formula: 3-1-2-2. Setae $3 c$ and $4 c$ and their alveoli absent. All setae setiform, thin, $1 a, 2 a$ and $3 a$ heavily barbed, $1 b, 3 b$ and $4 a$ slightly barbed, $1 c$ and $4 b$ indistinctly barbed; setae $1 b$ (24-28) longer than $3 b$ and $4 a$ (16-20) and other setae (10-12). Pedotecta I and II represented by small laminae. Custodia (cus) knife-like, distinct. Discidia (dis) elongate triangular. Circumpedal carinae $(c p)$ very long, reach the anterior margin of ventral plate.

Anogenital region. Four pairs of genital $\left(g_{1}\right.$, $\left.12-16 ; g_{2}-g_{4}, 8-10\right)$, one pair of aggenital (ag, 12-14), two pairs of anal $\left(a n_{1}, a n_{2}, 12-16\right)$ and three pairs of adanal $\left(a d_{1}-a d_{3}, 16-18\right)$ setae setiform, thin, indistinctly barbed. Adanal lyrifissures ( $\mathrm{iad})$ located close and parallel to anal plates.

Legs. Morphology typical for Perscheloribates (see Ermilov et al. 2011). Claw of each leg with small barbs on dorsal side. Porose areas on femora and trochanters III, IV present, but poorly visible. Formulas of leg setation and solenidia: I (1-5-34-20) [1-2-2], II (1-5-2-4-15) [1-1-2], III (2-3-1-3-15) [1-1-0], IV (1-2-2-3-12) [0-1-0]; homology of setae and solenidia indicated in Table 1. Famulus short, thin, straight, indistinctly dilated distally. Solenidia $\omega_{1}$ on tarsi I, $\omega_{1}$ and $\omega_{2}$ on tarsi II and $\sigma$ on genua III thickened, blunt-ended, other solenidia longer, setiform.

Material examined. Holotype (male) and one paratype (female): Cuba, Parque Nacional Alejandro de Humboldt, $20^{\circ} 30^{\prime} \mathrm{N}, 74^{\circ} 40^{\prime} \mathrm{W}$, leaf litter in forest. Six paratypes (three females and three males): Cuba, Valle de Viñales National Park, $22^{\circ} 40^{\prime} 56.8^{\prime \prime} \mathrm{N}, 83^{\circ} 42^{\prime} 57.5^{\prime \prime} \mathrm{W}$, Ancon, leaf litter in forest. Seven paratypes (three females and four males): Cuba, Cayo Santa Maria, 22 ${ }^{\circ} 66^{\prime} 21^{\prime \prime}$ N, $78^{\circ} 96^{\prime} 88^{\prime \prime} \mathrm{W}$, leaf litter in forest. The material was kept in the insufficiently labeled collections of the late Dr. Lidia Golosova at Tyumen State University Museum of Zoology.

Type deposition. The holotype is deposited in the collection of the Senckenberg Institution, Frankfurt, Germany; 14 paratypes are deposited in the collection of the Tyumen State University Museum of Zoology, Tyumen, Russia.

Etymology. The specific epithet curiosus refers to the unique presence of custodia.

Remarks. Perscheloribates (Perscheloribates) curiosus Ermilov sp. n. differs from all other species of the genus Perscheloribates (Perscheloribates) by the presence of well-developed custodia (vs. absent).

Perscheloribates (Perscheloribates) curiosus Ermilov sp. n. is morphologically most similar to P. (Perscheloribates) luzonensis Corpuz-Raros, 1980 from the Philippines (Corpuz-Raros 1980) in having small body size, the presence of pointed 
Table 1.

Leg setation and solenidia of Perscheloribates (Perscheloribates) curiosus Ermilov sp. $\mathrm{n}$.

\begin{tabular}{|l|l|l|l|l|l|}
\hline Leg & \multicolumn{1}{|c|}{$\operatorname{Tr}$} & \multicolumn{1}{|c|}{$\mathrm{Fe}$} & \multicolumn{1}{|c|}{$\mathrm{Ge}$} & \multicolumn{1}{|c|}{ Ti } & \multicolumn{1}{c|}{ Ta } \\
\hline I & $v^{\prime}$ & $d,(l), b v^{\prime \prime}, v^{\prime \prime}$ & $(l), v^{\prime}, \sigma$ & $(l),(v), \varphi_{1}, \varphi_{2}$ & $(f t),(t c),(i t),(p),(u),(a), s,(p v), v^{\prime},(p l), l^{\prime \prime}, \varepsilon, \omega_{1}, \omega_{2}$ \\
\hline II & $v^{\prime}$ & $d,(l), b v^{\prime \prime}, v^{\prime \prime}$ & $(l), \sigma$ & $(l),(v), \varphi$ & $(f t),(t c),(i t),(p),(u),(a), s,(p v), \omega_{1}, \omega_{2}$ \\
\hline III & $l^{\prime}, v^{\prime}$ & $d, l^{\prime}, e v^{\prime}$ & $l^{\prime}, \sigma$ & $l^{\prime},(v), \varphi$ & $(f t),(t c),(i t),(p),(u),(a), s,(p v)$ \\
\hline IV & $v^{\prime}$ & $d, e v^{\prime}$ & $d, l^{\prime}$ & $l^{\prime},(v), \varphi$ & $f t^{\prime \prime},(t c),(p),(u),(a), s,(p v)$ \\
\hline
\end{tabular}

Roman letters refer to normal setae, Greek letters - to solenidia (except $\varepsilon=$ famulus). Single prime (') marks setae on anterior and double prime (') - setae on posterior side of the given leg segment. Parentheses refer to a pair of setae. $\mathrm{Tr}$ - trochanter, $\mathrm{Fe}$ - femur, Ge-genu, Ti-Tibia, Ta-tarsus.

rostrum and short, rudimentary parts of translamellar line, and the absence of prolamellae. However, the new species differs from the latter by the bothridial setae pointed distally (vs. rounded in $P$. (Perscheloribates) luzonensis) and well visible notogastral setae (vs. posterior setae hardly visible, other setae represented by alveoli in P. (Perscheloribates) luzonensis).

Also, Perscheloribates (Perscheloribates) curiosus Ermilov sp. n. is morphologically similar to $P$. (Oxyscheloribates) aculeatus Hammer, 1961 from Peru (Hammer 1961) and P. (Ecuadoribates) pentasacculus Ermilov et Kalúz, 2012 from Ecuador (Ermilov and Kalúz 2012) in having apically pointed rostrum and the absence of prolamellae. However, the new species differs from both by the presence of narrowly protruding and pointed rostrum (vs. acutely pointed in $P$. (Oxyscheloribates) aculeatus and $P$. (Ecuadoribates) pentasacculus), short, rudimentary parts of translamellar line (vs. absent in $P$. (Oxyscheloribates) aculeatus and $P$. (Ecuadoribates) pentasacculus) and well visible notogastral setae (vs. only $p_{1} P$. (Oxyscheloribates) aculeatus, setae represented by alveoli in $P$. (Ecuadoribates) pentasacculus).

\section{ACKNOWLEDGEMENTS}

We cordially thank Dr. Otilia Ivan (Institute of Biological Research, Iasi, Romania) for loaning the paratypes of Scheloribates (Scheloribates) feideri Călugăr et Vasiliu, 1983 and Dr. Dania Prieto (University of Havana, Havana, Cuba) for collaboration.

\section{REFERENCES}

Balogh, J. and Balogh, P. 1990. Oribatid mites of the Neotropical region. II. Budapest, Akadémiai Kiadó Press, 333 pp.
Balogh, J. and Balogh, P. 1992. The Oribatid Mites Genera of the World. Vol. 1. Budapest, Hungarian National Museum Press, 263 pp.

Balogh, J. and Balogh, P. 2002. Identification Keys to the Oribatid Mites of the Extra-Holarctic Regions. Vol. 1. Miskolc, Well-Press Publishing Limited, $453 \mathrm{pp}$.

Călugăr, M. and Vasiliu, N. 1983. Une nouvelle contribution à la connaissance de la faune d'Oribates (Acarina: Oribatei) du karst de Cuba. Résultats des expéditions biospélogiques Cubano-Roumanies à Cuba, 4: 155-165.

Corpuz-Raros, L. 1980. Philippine Oribatei (Acarina) V. Scheloribates Berlese and related genera (Oribatulidae). Kalikasan, 9 (2-3): 169-245.

Ermilov, S.G. 2016. New species and records of oribatid mites of the superfamily Oripodoidea (Acari, Oribatida) from Cuba. Systematic and Applied Acarology, 21 (4): 450-460.

Ermilov, S.G. and Kalúz, S. 2012. A new subgenus and three new species of oribatid mites of the family Scheloribatidae (Acari: Oribatida) from Ecuador. Annales Zoologici, 62 (4): 773-787.

Ermilov, S.G. and Martens, J. 2014. A new species of Perscheloribates (Acari, Oribatida, Scheloribatidae) from Nepal with a key to all species of the genus from the Oriental region. Acarina, 22 (1): 14-19.

Ermilov, S.G., Rybalov, L.B. and Franke, K. 2011. Ethiopian oribatid mites of the family Scheloribatidae (Acari: Oribatida). African Invertebrates, 52 (2): 311-322.

Ermilov, S.G., Alvarado-Rodríguez, O., Tolstikov, A.V. and Retana-Salazar, A.P. 2015. Two new species of Scheloribatidae (Acari, Oribatida) from Costa Rica. Systematic and Applied Acarology, 20 (4): 399-409.

Ermilov, S.G., Sandmann, D., Marian, F. and Maraun, M. 2013. Perscheloribates paratzitzikamaensis $n$. sp., with supplementary descriptions of Scheloribates elegans and Monoschelobates parvus (Acari, 


\section{S. G. Ermilov and A. V. Tolstikov}

Oribatida, Scheloribatidae) from Ecuador. Acarologia, 53 (4): 429-437.

Hammer, M. 1961. Investigations on the oribatid fauna of the Andes Mountains. II. Peru. Det Kongelige Danske Videnskabernes Selskab Biologiske Skrifter, 13 (1): 1-157.

Hammer, M. 1973. Oribatids from Tongatapu and Eua, the Tonga Islands, and from Upolu, Western Samoa. Det Kongelige Danske Videnskabernes Selskab Biologiske Skrifter, 20 (3): 1-70.
Norton, R.A. and Behan-Pelletier, V.M. 2009. Oribatida. In: Krantz, G.W. and Walter, D.E. (Editors). A Manual of Acarology (TX): Lubbock, Texas University Press. Chapter 15: 430-564.

Subías, L.S. 2004. Listado sistemático, sinonímico y biogeográfico de los ácaros oribátidos (Acariformes: Oribatida) del mundo (excepto fósiles). Graellsia, 60 (número extraordinario): 3-305. Online version accessed in March 2015, $587 \mathrm{pp}$. 